\title{
DIVULGAÇÃO DE INFORMAÇÕES SOBRE RELACIONAMENTOS NA CADEIA DE SUPRIMENTO: UM ESTUDO SOB A PERSPECTIVA DA ECONOMIA DOS CUSTOS \\ DE TRANSAÇÃO
}

\author{
DISCLOSURE OF INFORMATION ON RELATIONSHIPS IN THE SUPPLY CHAIN: A \\ STUDY UNDER THE PERSPECTIVE OF THE ECONOMY OF TRANSACTION COSTS
}

\author{
DIVULGACIÓN DE INFORMACIÓN SOBRE RELACIONES EN LA CADENA DE \\ SUMINISTRO: UN ESTUDIO BAJO LA PERSPECTIVA DE LA ECONOMÍA DE LOS \\ COSTES DE TRANSACCIÓN
}

Karla Katiuscia Nobrega de Almeida, Programa de Pós-Graduação em

Ciências Contábeis

(UFPB), João Pessoa, PB, Brasil

Antônio André Cunha Callado, Programa de Pós-Graduação em

Ciências Contábeis

(UFPB), João Pessoa, PB, Brasil

Artigo Submetido em 13.11.2017. Aprovado em 16.05.2018.

Avaliado pelo processo de double blind review

e-mail para contato: kknalmeida@gmail.com

\begin{abstract}
RESUMO
O objetivo deste artigo foi analisar, sob a ótica da Teoria dos Custos de Transação, os mecanismos de controle sobre o relacionamento com fornecedores que são divulgados pelas companhias elétricas listadas na BM\&FBovespa. Para tanto, analisou-se o conteúdo dos relatórios de sustentabilidade do ano de 2014 de 18 geradoras e transmissoras de energia elétrica listadas na BM\&FBovespa, na seção de "relacionamentos com fornecedores", cujas categorias de análise basearam-se nas exigências do Manual de Contabilidade do Setor Elétrico, versão 2015. Observou-se indícios dos tipos híbrido e hierárquico (bilateral) como estrutura de governança da transação adotada e importância dada à divulgação de ações de monitoramento, o que pode sinalizar o entendimento de mecanismos para preencher as lacunas contratuais e realizar as adaptações necessárias às circunstancias. Ao cotejar esses mecanismos de controle com as práticas de controle gerencial se percebeu coincidência apenas em relação à avaliação de desempenho de fornecedores.
\end{abstract}

Palavras-Chave: Teoria dos Custos de Transação. Fornecedores. Relatório de Sustentabilidade.

\section{ABSTRACT}

This study aim to analyse the control mechanisms over the relationship with suppliers that are disclosed by the electric companies listed on BM\&FBovespa from the Transaction Cost Theory point of view. Therefore, it was analysed the content of the 2014 sustainability reports of 18 electricity generator and transmitter companies listed on the BM \& FBovespa, which was in the "supplier relationships" section whose analysis category were based on the requirements of the Accounting Manual of the Electric Sector, version 2015. About the governance structure of the transaction adopted and the importance given to the disclosure of monitoring actions, the evidences observed show hybrid and hierarchical types. This may signalize the knowledge of mechanisms to fill the contractual gaps and make the necessary adjustments to the circumstances. When confronting these control mechanisms with the practices of management control, it was noticed coincidence only in relation to the performance evaluation of suppliers.

Keywords: Transaction Cost Theory. Suppliers. Sustainability report. 


\title{
(9)REUNIR
}

\begin{abstract}
RESUMEN
El objetivo de este artículo fue analizar, bajo la óptica de la Teoría de los Costos de Transacción, los mecanismos de control sobre la relación con proveedores que son divulgados por las compañías eléctricas listadas en la BM \& FBovespa. Para eso, se analizó el contenido de los informes de sostenibilidad del año 2014 de 18 generadoras y transmisoras de energía eléctrica listadas en la BM \& FBovespa, en la sección de "relaciones con proveedores", cuyas categorías de análisis se basaron en las exigencias del Manual de Contabilidad del Sector Eléctrico, versión 2015. Fueron observados indicios de los tipos híbrido y jerárquico como estructura de gobierno de la transacción adoptada e importancia dada a la divulgación de acciones de seguimiento. Eso puede señalar la comprensión de mecanismos para llenar las deficiencias contractuales y realizar las adaptaciones necesarias a las circunstancias. Al comparar esos mecanismos de control con las prácticas de control de gestión se percibió coincidencia sólo frente a la evaluación de desempeño de proveedores.
\end{abstract}

Palabras clave: Teoría de los Costos de Transacción. Proveedores. Informe de Sostenibilidad.

\section{INTRODUÇÃO}

A Teoria Institucional em uma das suas vertentes, a Nova Economia Institucional, dedica atenção aos custos de transação e, conforme considera Williamson (1979), está preocupada com as origens, incidência e ramificações de tais custos, afirmando a proposição de que os custos de transação são fundamentais para o estudo da economia. Dentre outros intuitos, Williamson (1979) descreve as principais estruturas de governança de transações, entendida como o framework institucional no qual a totalidade de uma transação é decidida, sendo mercados e hierarquias suas duas principais alternativas.

Na perspectiva da Economia dos Custos de Transação, conforme explica Fiani (2002, p. 283) um movimento de uma empresa no sentido de integração vertical com um fornecedor objetiva economizar em custos de transação. Tais custos são aqueles que os agentes enfrentam toda vez que recorrem ao mercado, ao negociar, redigir e garantir o cumprimento de um contrato (Fiani, 2002). No entanto, há dificuldades quando da negociação e redação do contrato, bem como da garantia de sua execução, provenientes da racionalidade limitada e oportunismo dos agentes, complexidade e incerteza ambiental, e especificidade de ativos.

No que se refere à especificidade de ativos, Quintart e Zisswiller (1985) consideram constituir-se no elemento determinante do custo de transação, entendendo que um ativo é tanto mais específico quanto mais limitado for o seu campo de utilização no processo industrial ou no processo comercial. A lógica básica é que o aumento da especificidade do ativo, juntamente com o aumento da incerteza, precisam de mecanismos mais complexos e dispendiosos de governança, ao passo que quando a incerteza for baixa e não houver ativos específicos, haverá menores custos de transação (WILLIAMSON, 2004 citado por BARBOSA, 2012).

O ambiente no qual está inserida a indústria de geração e distribuição de energia elétrica oferece exemplo de especificidade de ativos por possuírem, conforme lembram 


\section{(9)REUNIR}

Santana e Oliveira (1999) usinas hidro ou termelétricas sem uso alternativo, que não a geração de energia elétrica, e estão necessariamente, em especial no caso das hidrelétricas, localizadas próximo da fonte do combustível, assim como a forma de interligação das redes para o sistema de distribuição de energia que é bastante complexa, requerendo forte coordenação central para viabilizar o escoamento da energia que está sendo oferecida e demandada a cada instante.

Tais exemplos de especificidade de ativos podem demandar relacionamentos com seus fornecedores através de mecanismos contratuais complexos e dispendiosos para negociação e execução dos contratos, portanto com maiores custos de transação, motivo pelo qual a presente pesquisa se dedica ao estudo do campo organizacional das companhias de energia elétrica e seus fornecedores.

Quando se trata de informações da contabilidade no contexto interorganizacional, além de seu papel gerencial e de controle, também há o seu papel comunicador aos stakehorlders, cujos documentos a eles divulgados podem contribuir para entendimento dos seus relacionamentos interorganizacionais que, analisados à luz da economia dos custos de transações, podem contribuir para melhor conhecimento do impacto das práticas de controle socialmente construídas sobre esses relacionamentos.

Nesta perspectiva, indaga-se "Quais mecanismos de controle sobre 0 relacionamento com fornecedores são divulgados pelas companhias elétricas listadas na BM\&FBovespa?". Como objetivo geral, tem-se: analisar, sob a ótica da Teoria dos Custos de Transação, os mecanismos de controle sobre o relacionamento com fornecedores que são divulgados pelas companhias elétricas listadas na BM\&FBovespa, em seus relatórios de sustentabilidade.

Alves et al. (2013) corroborando com autores que citam, comentam que muito pouca atenção tem sido dada à gestão dos relacionamentos interorganizacionais, como também àqueles acordos caracterizados por uma empresa mais poderosa em relação a outros parceiros, sendo o papel dos mecanismos de controle, em suas várias formas, ainda mal compreendido. Assim, essa pesquisa se justifica ao voltar seu olhar para essas questões, na tentativa de fomentar o debate.

\section{FUNDAMENTAÇÃO TEÓRICA}

Esta seção aborda o embasamento teórico que sustenta o presente artigo, apresentando uma breve discussão sobre as relações contratuais interorganizacionais sob a perspectiva da Economia dos Custos de Transação e a inserção da Contabilidade Gerencial e Controle Gerencial nesse contexto.

\subsection{Relações Contratuais pela Lente da Economia dos Custos de Transação}

Utilizando-se da classificação tripla dos contratos proposta por Macneil, Williamson (1979) considera as categorias clássicas, neoclássicas e relacionais do direito contratual, em que a ênfase da primeira, contratação clássica, é sobre as regras legais, documentos formais e transações de auto-liquidação; $\mathrm{Na}$ categoria neoclássica, reconhece-se que alguns contratos nunca serão alcançados a menos que ambas as partes tenham confiança nos 


\section{(9)REUNIR}

mecanismos contratuais; Por sua vez, a contratação relacional tem seu ponto de referência a relação inteira como ela se desenvolveu através do tempo, e não o acordo original, como nas classificações anteriores, alcançando, assim, uma vasta gama de normas além daquelas centradas no intercâmbio e seus processos imediatos.

O modelo williamsoniano apresenta três estruturas alternativas de governança, mercado, híbridos e hierarquia, que faz correspondência com a classificação tripla dos contratos. Conforme explica Hennart (2014), as transações de mercado são governadas pela lei contratual clássica, enquanto que as formas híbridas de governança são apoiadas pela lei neoclássica contratual e a hierarquia se apoia na contratação relacional.

Diante da variedade e complexidade das relações contratuais e estruturas de governança, Williamson (1979) adiciona que as dimensões críticas para descrever as transações, objeto das relações contratuais, são: a incerteza, a frequência das transações e o grau em que os investimentos são idiossincráticos. A lógica é que as estruturas de governança precisam ser alinhadas a essas características. Assim, a hierarquia é preferível quando a especificidade de ativos e a incerteza forem altas, e de frequência recorrente; a governança de mercado é adequada quando a especificidade de ativos for baixa a incerteza for alta, seja a frequência ocasional ou recorrente; e quando ambas (especificidade de ativos e incerteza) alcançarem níveis intermediários e a frequência for ocasional, a governança híbrida é ideal. (WILLIAMSON, 1979; HENNART, 2014).

Para a estrutura de governança altamente específica, Williamson (1979) ainda distingue dois tipos dessa estrutura, a governança bilateral e a governança unificada. A governança bilateral, é explicada por Fiani (2002) como um contrato de relação onde as partes preservam sua autonomia e não se preocupam em elaborar contratos detalhados, bastando estabelecer metas e objetivos a serem alcançados, condições gerais de execução contratual e mecanismos para resolução de conflitos, caso ocorram. Williamson (1981) ensina que, quando a especificidade dos ativos é grande, o comprador e o vendedor vão fazer esforços especiais para projetar uma troca que tem boas propriedades de continuidade.

Já a governança unificada, esclarece Williamson (1979), dá-se quando a operação é afastada do mercado e organizada dentro da empresa sujeita a uma relação de autoridade, ou seja, hierarquia (integração vertical), abrigando transações que se tornam progressivamente mais idiossincráticas, uma vez que os recursos humanos e físicos especializados se tornam mais especializados para um único uso e, portanto, menos transferíveis para outros usos. Fiani (2002, p. 278) lembra que "a probabilidade da opção por uma estrutura unificada e hierarquizada cresce com o caráter idiossincrático do investimento".

Esse caráter idiossincrático tem seus fatores determinantes alvo da atenção de Williamson (1981) segundo o qual este surge em qualquer das três formas principais: especificidade de localização, especificidade física e especificidade de ativos humanos. A especificidade de localização na concepção de Williamson (1981) corresponde a estações sucessivas localizadas em relação face-a-face uma à outra, de modo a economizar em despesas de estoque e transporte; a especificidade física, como matrizes especializadas necessárias para produzir um componente, cujas características de desingn podem reduzir o valor do ativo em uma aplicação alternativa; e especificidade de capital humano que surgem 


\section{(9)REUNIR}

de processos "aprender fazendo" dos empregados de uma empresa. (WILLIAMSON, 1981; FIANI, 2002).

Além das características dimensionadoras das transações, Williamson (1979, 1981, 2007) reflete sobre pressupostos comportamentais, em que a racionalidade limitada e o oportunismo são elementos centrais. Por racionalidade limitada Fiani (2002) entende como limitações neurofisiológica e linguística do comportamento humano que atrai a atenção da Teoria dos Custos de Transação nas condições de complexidade e incerteza que, por sua vez, gera assimetrias de informação entre as partes envolvidas na transação, podendo afetar seu resultado.

Fiani (2002, p. 270) explica que a manipulação de assimetrias de informação, visando apropriação de fluxos de lucros está associada ao oportunismo, entendido como "transmissão de informação seletiva, distorcida e promessas "autodesacreditadas" sobre o comportamento futuro do próprio agente" geradoras de problemas na execução e renovação contratuais. Quintart e Zisswiller (1985, p.341) corroboram esse entendimento, argumentando que "os custos de elaboração e de controle de contratos complexos, pela via do mercado, variam consideravelmente com as características dos decisores (racionalidade limitada e oportunismo) e com as características do mercado no qual esses decisores operam".

\subsection{A Contabilidade e o Controle Gerenciais no Contexto Interorganizacional}

Na perspectiva da análise das relações contratuais entre organizações, o controle gerencial e a contabilidade gerencial também se fazem presentes. Mouritsen e Thrane (2006) entendem que o controle gerencial e a contabilidade estão envolvidos no planejamento integrado e relações da cadeia de suprimentos, redução de custos, desenvolvimento de produtos entre empresas e acordos de terceirização, assim como na análise do modo de governança da rede e estão relacionados à confiança e lealdade, de modo que a contabilidade geralmente pode ajudar a ser exercida a justiça.

Dekker (2016) baseado em uma revisão de estudos de contabilidade gerencial que se concentram nas relações entre empresas, identifica três áreas-chave em que a pesquisa em contabilidade gerencial intrafirma e interfirmas se conectam e, particularmente, como esses campos podem se conectar melhor, que são: o papel das práticas de contabilidade e controle gerencial no âmbito das relações entre empresas; interrelações entre práticas de contabilidade e controle gerencial intrafirma e interfirma, e o uso do framework de sistema de controle gerencial intrafirma para examinar o uso de controles gerenciais interfirma entre parceiros de negócios.

Dekker (2016) observa que estudos sobre contabilidade gerencial interfirmas tem sido influenciados significativamente por estudos relacionados a áreas afins, tais como economia, estratégia e gestão, que têm na sua maioria abordados questões em nível da empresa, tais como sobre os limites da empresa (por exemplo, a escolha entre fazercompra-ou-aliar-se, e entre joint ventures e alianças não representativas de capital), estratégias colaborativas de empresas (por exemplo, gestão do crescimento, a entrada no mercado, inovação, transferência de conhecimentos e de risco através da colaboração), e a aquisição de recursos estratégicos através dos parceiros de negócios. 
Lopes et al. (2014) identificaram as práticas de contabilidade interorganizacional adotadas em 55 indústrias de médio e grande porte da Região Metropolitana do Recife, em que as previsões de demandas foram a informação mais compartilhada, o meio mais usual é através de e-mails, seguido de reuniões face a face e as informações de cunho financeiro foram aquelas com menor frequência de compartilhamento, tanto com clientes quanto com fornecedores e operadores logísticos. Entre estes, divergiram a periodicidade de compartilhamento das informações gerenciais, que com clientes acontece diariamente e a maioria das empresas não possui regularidade de compartilhamento com fornecedores e operadores logísticos.

Pereira (2014) investigou como é realizado o Controle Gerencial em uma Rede de Negócios caracterizada por uma estrutura de franquia, cujos resultados contemplam a identificação de elementos caracterizadores, facilitadores, tais como engajamento institucional da rede em associações de livreiros, a busca por rentabilidade e fluxo financeiro, existência de uma diretoria financeira desempenhando também funções de controller, dentre outros. Pereira (2014) concluiu que diversos mecanismos de Controle Gerencial, formais (orçamento, fluxo de caixa, declaração de missão, declaração de valores e conciliações de informação) ou informais (reuniões com franqueados, diretores e empregados), foram implementados.

Do exposto, observa-se que a Contabilidade pode está presente nas relações interorganizacionais quando do compartilhamento de informações, na avaliação do desempenho e incentivando a colaboração entre os parceiros, dentre outros, podendo contribuir com a continuidade e o aprofundamento da cooperação entre os parceiros do arranjo interorganizacional.

\section{MÉTODO DE PESQUISA}

Sob tipologia adotada por Beuren (2004), este estudo tem características de pesquisa descritiva, bibliográfica e documental, com abordagem qualitativa. A pesquisa documental se materializou por meio da coleta de informações nos Relatórios de Sustentabilidade das empresas da amostra, referente ao ano de 2014.

A escolha pelo campo organizacional pesquisado se deve a especificidade de ativos está presente nas transações realizadas nele, uma vez que esta característica se configura como um dos elementos determinantes do custo de transação. De acordo com as Leis n. $\mathrm{o}$ 10.847 e 10.848, ambas de 2004, as atividades típicas do setor elétrico brasileiro são geração, transmissão, distribuição e comercialização de energia elétrica. Para tais atividades, o uso de equipamentos que compõem as usinas de geração de energia, as linhas de transmissão, redes, transformadores e subestações de distribuição, oferecem exemplos de ativos específicos transacionados pelas companhias elétricas.

Para os propósitos aos quais se destinam este estudo, optou-se por considerar as companhias de geração e transmissão de energia elétrica, que de uma população de 63 empresas listadas na BM\&FBovespa, 29 se ocupam dessas duas atividades, sendo que algumas delas fazem parte de um mesmo grupo econômico, cujo relatório de sustentabilidade é único para o grupo. Além disto, a disponibilidade do relatório de 


\section{(9)REUNIR}

sustentabilidade para o ano de 2014, nos sites pesquisados, também colaboraram para reduzir a amostra final para 18 entidades, sendo dois grupos e 16 empresas.

Os relatórios de sustentabilidade para o ano de 2014, foram obtidos diretamente do banco de dados da Global Reporting, ou nos sites institucionais das empresas da amostra, caso estas não tivessem disponibilizados seus relatórios no referido banco de dados. Ressalta-se que a Light foi a única empresa que só foi possível coletar o relatório referente a 2015. As informações observadas foram coletadas na seção "Relacionamento com Fornecedores".

Como técnica de análise, elegeu-se a análise de conteúdo, cujas categorias de análise compreenderam os itens descritos no quadro 1 , elaborados com base nas exigências do Manual de Contabilidade do Setor Elétrico, versão 2015.

\begin{tabular}{|c|c|c|}
\hline Informação & Comentário & $\begin{array}{c}\text { Indicador } \\
\text { GRI }\end{array}$ \\
\hline $\begin{array}{l}\text { Critérios de seleção e } \\
\text { avaliação de } \\
\text { fornecedores }\end{array}$ & $\begin{array}{l}\text { Exigência de padrões de conduta nas relações com os trabalhadores } \\
\text { (incluindo o combate ao trabalho infantil e ao trabalho forçado), ou } \\
\text { com o meio ambiente (que contribuam com o desenvolvimento } \\
\text { sustentável do planeta) }\end{array}$ & $\begin{array}{l}\text { HR1 } \\
\text { HR6 } \\
\text { HR7 }\end{array}$ \\
\hline $\begin{array}{l}\text { Método para segregação } \\
\text { de fornecedores }\end{array}$ & \multicolumn{2}{|c|}{$\begin{array}{l}\text { Segregação de acordo com a relevância na cadeia produtiva, incluindo critérios } \\
\text { para definição dos fornecedores críticos. Identificação do perfil: porte das } \\
\text { empresas (pequena, média e grande, por número de empregados), e as principais } \\
\text { atividades realizadas para a Outorgada. }\end{array}$} \\
\hline Ações de monitoramento & $\begin{array}{l}\text { Visam verificação do cumprimento de normas legais relativas aos } \\
\text { produtos fornecidos e aos empregados terceirizados; critérios de } \\
\text { responsabilidade socioambiental; percentual de empresas } \\
\text { contratadas e fornecedores críticos que foram submetidos a } \\
\text { avaliações referentes a direitos humanos e às medidas tomadas. }\end{array}$ & HR2 \\
\hline $\begin{array}{l}\text { Canais e políticas de } \\
\text { relacionamento; }\end{array}$ & \multicolumn{2}{|c|}{$\begin{array}{l}\text { Canais e formas de relacionamento utilizadas para estabelecer comunicação com } \\
\text { seus fornecedores. }\end{array}$} \\
\hline $\begin{array}{l}\text { Política e mecanismos de } \\
\text { estímulo e incentivo }\end{array}$ & $\begin{array}{l}\text { Refere-se aos compromissos da empresa perante a sociedade e } \\
\text { alinhamento aos objetivos estratégicos da empresa, especialmente } \\
\text { em relação aos aspectos: qualidade na prestação dos serviços, } \\
\text { segurança no trabalho, satisfação dos clientes, respeito à comunidade } \\
\text { e ao meio ambiente. }\end{array}$ & $\begin{array}{l}\text { HR3 } \\
\text { EU16 } \\
\text { EU18 }\end{array}$ \\
\hline $\begin{array}{l}\text { Políticas, práticas e } \\
\text { proporção de gastos com } \\
\text { fornecedores locais }\end{array}$ & \multicolumn{2}{|l|}{ Apresentado, na pesquisa, como perfil dos fornecedores. } \\
\hline $\begin{array}{l}\text { Apoio ao } \\
\text { desenvolvimento de } \\
\text { fornecedores }\end{array}$ & \multicolumn{2}{|c|}{$\begin{array}{l}\text { Política de auxílio ao desenvolvimento de pequenas e microempresas, priorizando- } \\
\text { as ao escolher seus fornecedores e auxiliando-as a desenvolverem seus processos } \\
\text { produtivos e de gestão. }\end{array}$} \\
\hline
\end{tabular}

Quadro 1 - Tipo de informações coletadas nos relatórios de sustentabilidade analisados.

Fonte: Elaboração própria, baseada no Manual de Contabilidade do Setor Elétrico (2015)

As informações categorizadas foram analisadas à luz de constructos da Economia do Custo de Transação, que se referem aos tipos de estrutura de governança da transação, redução de custos de transação e extensão dos mecanismos de monitoramento/controle de acordo com a necessidade de cada tipo de estrutura de governança. 


\section{(9)REUNIR}

Adicionalmente, comparou-se os mecanismos de controle identificados com os previstos na literatura de controle gerencial nos relacionamentos interorganizacionais, conforme descrito no quadro 2.

\begin{tabular}{|l|l|}
\hline Práticas de Controle Gerencial & Autores \\
\hline Incentivos aos boundary spanners & Dekker (2016) \\
\hline Estabelecimento de metas & Bedford, Marmi e Sandelin (2016) \\
\hline $\begin{array}{l}\text { Previsões de demandas, comparações entre o orçamento planejado e } \\
\text { o real, ciclo de tempo, informações de custos de produtos. }\end{array}$ & Lopes et al. (2014) \\
\hline $\begin{array}{l}\text { Orçamentos interorganizacionais, custeio alvo, sistema de gestão de } \\
\text { custos }\end{array}$ & Gonzaga et al. (2014) \\
\hline Medição de desempenho no contexto da cadeia de suprimento & $\begin{array}{l}\text { Bhagwat e Sharma (2007) } \\
\text { Chia, Goh e Hum (2009) } \\
\text { Callado e Jack (2015) }\end{array}$ \\
\hline
\end{tabular}

Quadro 2 - Práticas de Controle Gerencial consideradas no estudo.

Os resultados obtidos são descritos e analisados conforme seção a seguir.

\section{ANÁLISE E DISCUSSÃO DOS RESULTADOS}

Inicialmente, observou-se o perfil dos fornecedores descrito pelas empresas estudadas, quanto ao porte, prioridades e o quantitativo destes, entre fornecedores ativos e fornecedores críticos, conforme quadro 3.

Observa-se heterogeneidade das informações disponibilizadas pelas empresas da amostra, em seus relatórios de sustentabilidade, quanto a aspectos dos seus fornecedores, em que $78 \%$ delas divulgaram pelo menos uma das informações dispostas no quadro 3, e as que o fizeram nenhuma apresentou todos os itens. As informações mais divulgadas por $50 \%$ das empresas se referiram ao quantitativo de fornecedores ativos e menção sobre a priorização de fornecedores, especialmente os locais. Tais informações revelam a adesão dessas companhias ao solicitado no Manual de Contabilidade do Setor Elétrico quanto à identificação do perfil e quanto às políticas e práticas com fornecedores locais.

\begin{tabular}{|c|c|c|c|c|}
\hline Empresa & Quantitativo & $\begin{array}{c}\text { Fornecedores } \\
\text { Críticos }\end{array}$ & $\begin{array}{c}\text { Porte das } \\
\text { Empresas } \\
\text { Fornecedoras }\end{array}$ & Fornecedores Prioritários \\
\hline AES TIETE & 1.400 & ND & $\begin{array}{c}\text { Pequeno, médio e } \\
\text { grande }\end{array}$ & $\begin{array}{c}\text { Fornecedores } \\
\text { Socioambientais }\end{array}$ \\
\hline AMPLA & ND & $\begin{array}{c}134(9 \% \text { do } \\
\text { total) }\end{array}$ & ND & $\begin{array}{c}\text { Fornecedores Locais (60,2\% } \\
\text { das empresas contratadas. }\end{array}$ \\
\hline CELP & $\begin{array}{c}16 \text { estratégicos (54\% } \\
\text { dos contratos } \\
\text { vigentes). }\end{array}$ & ND & ND & ND \\
\hline CEMIG & 632 & ND & Soc. de Econ. Mista, não há \\
\hline
\end{tabular}


(9REUNIR

\begin{tabular}{|c|c|c|c|c|}
\hline CESP & ND & ND & ND & $\begin{array}{c}\text { Não prioriza fornecedores } \\
\text { locais. }\end{array}$ \\
\hline COPEL & 5.744 & 140 & ND & $\begin{array}{c}\text { Fornecedores Locais (56,7\% } \\
\text { dos seus gastos com } \\
\text { fornecedores) }\end{array}$ \\
\hline CPFL & $\begin{array}{c}3.529(125 \\
\text { estratégicos) }\end{array}$ & 63 & ND & ND \\
\hline ELETROBRAS & ND & ND & ND & $\begin{array}{c}\text { Não prioriza. Compras diretas } \\
\text { com fornecedores locais. }\end{array}$ \\
\hline EMAE & ND & ND & ND & $\begin{array}{c}\text { Pequenas e Médias } \\
\text { Empresas. (Lei } \\
\text { Complementar 123). }\end{array}$ \\
\hline $\begin{array}{c}\text { GER } \\
\text { PARANAP }\end{array}$ & 1.178 & ND & ND & ND \\
\hline LIGHT & 1.585 & 190 & ND & ND \\
\hline RENOVA & ND & ND & ND & $\begin{array}{c}\text { Expectativa de aumento de } \\
\text { fornecedores locais. }\end{array}$ \\
\hline TRACTABEL & 1.217 & ND & ND & Fornecedores Locais \\
\hline CTEEP & $\begin{array}{c}219 \text { fornecedores } \\
1.100 \text { terceirizados }\end{array}$ & ND & ND & ND \\
\hline
\end{tabular}

Quadro 3 - Perfil dos Fornecedores relatados pelas companhias elétricas estudadas.

Fonte: Dados da pesquisa (2016). ND = não disponível

Em relação à priorização de fornecedores locais (entendido como sendo aqueles instalados no mesmo Estado ou Região da empresa), observa-se que estes podem contribuir para redução de custos, ao potencializar, por exemplo, redução de custos logísticos, portanto, indo além dos requisitos advindos da sua responsabilidade social para desenvolver o entorno no qual a empresa se insere, buscando alcançar vantagem competitiva. Conforme observam Uddin e Hassan (2011), através da colaboração com os seus parceiros, as empresas tentam alcançar vantagem de custo e vantagem competitiva sustentável em relação aos concorrentes.

No que se refere à informação sobre o quantitativo de fornecedores críticos, ressaltase os critérios divulgados pelas empresas para classificação nessa condição. Dentre estes, são considerados críticos fornecedores com contratos acima de 400 mil euros, que tenham possíveis impactos significativos nas operações da empresa (AMPLA) em relação a aspectos sociais, ambientais e econômicos (COPEL) e riscos operacionais ou reputacionais (CPFL). A título exemplificativo, no relatório da TAESA, é relatado que dentre os riscos operacionais da empresa, estão os relacionados com risco de construção e desenvolvimento de infraestruturas, tais como:

Atrasos na execução da obra ligados ao fato de dependerem de terceiros para fornecer os equipamentos utilizados em suas instalações e, por isso, estão sujeitas a aumentos de preços e falhas por parte de tais fornecedores, como atrasos na entrega dos equipamentos ou entrega de equipamentos avariados. Adicionalmente, devido às especificações técnicas dos equipamentos utilizados em suas instalações, há disponibilidade de poucos fornecedores e, para determinados equipamentos, há um único fornecedor. (TAESA, 2014) 


\section{(9REUNIR}

O objetivo com a pré-qualificação de fornecedores é diminuir o risco e a dependência operacional de fornecedores com conhecimento muito específicos e garantir maior eficiência e produtividade dos processos. (AES TIETE, 2014)

Na perspectiva da Teoria dos Custos de Transação, entende-se que a criticidade do fornecedor também decorre da possibilidade de seu comportamento oportunista quando do aumento de preços, e não cumprimento de todas as cláusulas contratuais, por exemplo, e em decorrência da especificidade de ativos transacionados, reduzindo o leque de opções de fornecedores, podendo causar o "problema do refém" abordado na literatura. Conforme explica Fiani (2002) este problema se verifica tanto na relação entre vendedor e comprador, como vice-versa e ocorre quando uma das partes que realizou um investimento em um ativo específico torna-se vulnerável a ameaças da outra parte de encerrar a relação, o que pode permitir obtenção de condições mais vantajosas do que as do início da transação.

Ressalta-se que das especificidades de ativos previstas por Williamson (1981) as citações acima se referem as especificidades física e de ativos humanos. Tais fatos demandam a adoção de maiores e melhores mecanismos de monitoramento e avaliação desses contratos, uma vez que, conforme explicam Uddin e Hassan (2011), por causa da presença de especificidade de ativos e a incerteza no processo de troca relacional, as relações interorganizacionais exigem mais mecanismos de governança extensiva.

Quanto aos critérios de seleção e avaliação de fornecedores, constatou-se que as empresas da amostra divulgaram suas práticas de contato inicial com seus fornecedores, estabelecendo procedimentos de cadastramento on line dos mesmos e sua posterior préqualificação/habilitação.

Tais procedimentos de cadastramento de fornecedores se dão on-line, por intermédio do website das empresas, com requisitos de segurança para criptografia dos dados, objetivando agilidade no processo, sendo esta uma etapa inicial que é sucedida por habitação/pré-qualificação do fornecedor cadastrado, podendo ocorrer com verificação in loco e posterior avaliação para fins de contratação. Apesar de ser essencial que o fornecedor aceite os termos contratuais, em que $100 \%$ das empresas analisadas divulgaram a exigência de adoção de padrões éticos e de responsabilidade social e ambiental, através de cláusulas contratuais, as condições comerciais definem a contratação.

Tais constatações, analisadas pela lente da Teoria dos Custos de Transação, sugere os seguintes aspectos: os procedimentos rígidos de seleção e avaliação de fornecedores adotados pela empresa focal (companhias elétricas), bem como suas exigências que transcendem as especificações técnicas da transação por abranger padrões éticos e de responsabilidade social e ambiental.

Outro aspecto analisado diz respeito às condições comerciais definirem a contratação, como não poderia deixar de ser. Pela ótica da Teoria dos Custos de Transação, quanto à estrutura de governança da transação adotada, observa-se indícios dos tipos híbrido e hierárquico (bilateral). As condições de mercado analisadas e a consideração de contratações relacionais, ao desejarem relacionamentos de longo prazo, exemplificativamente conforme relatório de sustentabilidade do Gurpo Neoenergia, que em suas relações com investidores declararam "construir parcerias de longo prazo, facilitando e promovendo o engajamento dos fornecedores aos valores da empresa, especialmente os de 


\section{(9)REUNIR}

segurança, pessoas, sustentabilidade e integridade", (NEONERGIA, 2014), na presença de especificidade de ativos, faz a governança híbrida adequada às transações das companhias elétricas da amostra.

Para fins exemplificativos e quanto aos critérios de avaliação de fornecedores, as empresas da amostra divulgaram informações sintetizadas no quadro 4.

\begin{tabular}{|c|c|}
\hline Empresa & Resumo dos Critérios de Avaliação \\
\hline AES TIETE & $\begin{array}{l}\text { Fornecedores avaliados pelo Índice de Desempenho do Fornecedor (IDF), que } \\
\text { pondera qualidade, respeito ao prazo, responsabilidade socioambiental, } \\
\text { certificações e inovação (sugerido pelo fornecedor), cujo resultado também é } \\
\text { considerado para o próximo processo de compra }\end{array}$ \\
\hline NEOENERGIA & Preocupa-se com a conformidade do fornecedor com a legislação vigente. \\
\hline CPFL & $\begin{array}{l}\text { Considera o Índice de Parceria (ÍNPAR), que envolve aspectos como satisfação dos } \\
\text { clientes e dos colaboradores, segurança, gestão empresarial e sustentabilidade }\end{array}$ \\
\hline GRUPO EDP & $\begin{array}{l}\text { Elaboração da matriz de risco relacionados à práticas trabalhistas, de direitos } \\
\text { humanos, sociais e ambientais. Aplicação de questionário em visita as instalações do } \\
\text { fornecedor para concluir cadastramento/verificação de atendimento as condições } \\
\text { contratuais. }\end{array}$ \\
\hline CELP & $\begin{array}{l}\text { Utilização do NEOCONTROLE que é um conjunto de indicadores ligados a aspectos } \\
\text { econômico-financeiros, trabalhistas e previdenciários, de saúde e segurança, de } \\
\text { qualidade do serviço, meio ambiente e de controle de materiais. }\end{array}$ \\
\hline CEMIG GT & $\begin{array}{l}\text { Utilização do Índice de Qualidade dos Serviços Contratados (IQSC), com } \\
\text { identificação de materiais, serviços e fornecedores de alto risco de sustentabilidade, } \\
\text { que é revisada anualmente. }\end{array}$ \\
\hline CESP & $\begin{array}{l}\text { No cadastramento, entre outros documentos são exigidos as demonstrações e será } \\
\text { feita avaliação econômico-financeira, com base nos índices de liquidez (corrente e } \\
\text { geral) e endividamento do ativo. }\end{array}$ \\
\hline COPEL & $\begin{array}{l}\text { Utilização de metodologia e mapeamento das categorias de fornecimento } \\
\text { consideradas críticas em relação a aspectos sociais, ambientais e econômicos. }\end{array}$ \\
\hline TRACTEBEL & $\begin{array}{l}\text { A Companhia não realiza processo de avaliação de seus fornecedores. Entretanto, } \\
\text { aqueles considerados críticos em relação a impactos ambientais são avaliados } \\
\text { semestralmente. Não há avaliação das operações quanto aos riscos relacionados à } \\
\text { corrupção. }\end{array}$ \\
\hline CTEEP & $\begin{array}{l}\text { São avaliados desde a sua qualificação para trabalhar com a companhia até a } \\
\text { finalização do serviço prestado ou entrega dos materiais adquiridos. }\end{array}$ \\
\hline
\end{tabular}

Quadro 4 - Trechos dos relatórios analisados que exemplificam e resumem os Critérios de Avaliação de Fornecedores divulgados nos relatórios analisados.

Fonte: Dados da pesquisa (2016)

Observa-se que $72 \%$ das empresas da amostra divulgaram em seus relatórios de sustentabilidade os critérios usados para avaliação dos seus fornecedores. Destaca-se a utilização de indicadores de desempenho que englobam critérios de atendimento a cláusulas contratuais e aquelas relativas à responsabilidade socioambiental, bem como os critérios técnicos de qualidade e prazo.

Percebe-se, pela leitura do quadro 4, que apenas uma das empresas, a CESP, cita a utilização de demonstrações contábeis para basear avaliação econômico-financeira através da extração de indicadores de liquidez e endividamento, o que pode sinalizar uma subutilização das informações contábeis para avaliação de fornecedores ou omissão de 


\section{(9)REUNIR}

divulgação dessas práticas. Em qualquer situação, perde-se a oportunidade de conhecer melhor e, consequentemente, explorar o papel da contabilidade nos relacionamentos interorganizacionais com fornecedores.

Adicionalmente, observa-se que a avaliação dos fornecedores ocorre tanto na fase do cadastramento e habilitação (pré-qualificação) quanto na execução contratual, sendo esta última a cargo de gestores de contratos, comitês internos de fornecedores, administradores de contrato, ou ficando sob a responsabilidade da gestão da área contratante, cujas atribuições se materializam nas ações de monitoramento.

Para fins exemplificativos, destaca-se conteúdo extraído de alguns dos relatórios analisados que versam sobre as ações de monitoramento de fornecedores implementadas pelas empresas da amostra, conforme descrito no quadro 5.

\begin{tabular}{|l|l|}
\hline Empresa & Resumo das Ações de Monitoramento \\
\hline AES TIETE & $\begin{array}{l}\text { Como parte dos benefícios do programa Parcerias Sustentáveis, está a inteligência da } \\
\text { gestão dos fornecedores por meio da análise cruzada das empresas mais estratégicas } \\
\text { para os negócios da AES Tietê, em que suas principal ferramenta é o Índice de } \\
\text { Desempenho do Fornecedor (IDF). Também são realizadas inspeções técnicas, } \\
\text { ambientais e de segurança, periodicamente, com o objetivo de auxiliar a companhia a } \\
\text { se antecipar aos riscos operacionais, de imagem e reputação, que podem vir a ser } \\
\text { causados por uma eventual postura inadequada dos fornecedores. }\end{array}$ \\
\hline CEEE-GT & $\begin{array}{l}\text { Os processos licitatórios, respectivos contratos, sua gestão e avaliação asseguram a } \\
\text { existência dos requisitos legais que visam garantir o cumprimento da legislação } \\
\text { trabalhista, de segurança, higiene e saúde no trabalho e a preservação do meio } \\
\text { ambiente. Realiza análise documental plena acerca da regularidade trabalhista nos } \\
\text { contratos em que há cessão de mão-de-obra. }\end{array}$ \\
\hline CELPE & $\begin{array}{l}\text { Auditorias, análise de documentos e controles internos. Inspeções sobre saúde e } \\
\text { segurança dos empregados terceirizados, direitos humanos. Acompanhamento } \\
\text { semestral dos suprimentos estratégicos consumidos. Os produtos recebidos são } \\
\text { inspecionados nas instalações da empresa fornecedora ou no almoxarifado da Celpe, a } \\
\text { fim de verificar se atendem aos requisitos técnicos necessários. }\end{array}$ \\
\hline TAESA & $\begin{array}{l}\text { A ferramenta SBM (Supply Base Management) foi aprimorada através de sua inserção } \\
\text { no SAP, proporcionando mais agilidade na atualização das informações de fornecedores } \\
\text { monitorados, consumo contratual, certificações, analise financeira e desempenho } \\
\text { técnico. Os critérios utilizados para o monitoramento destes fornecedores incluem } \\
\text { análise financeira, segurança, meio ambiente, desempenho técnico e riscos jurídicos. }\end{array}$ \\
\hline por base os requisitos contratuais assumidos.
\end{tabular}

Quadro 5-Trechos dos relatórios analisados que exemplificam as ações de monitoramento

Fonte: Dados da pesquisa (2016)

Ressalta-se 94\% de adesão das empesas analisadas quanto à divulgação de informação sobre suas ações de monitoramento de fornecedores, tornando este o tipo de informação mais evidenciada nos relatórios de sustentabilidade. Isto sugere a importância dada pelas empresas focais ao controle de suas relações interorganizacionais e contribui para ratificar o entendimento de se referirem às estruturas de governança do tipo híbrido e hierarquia (na forma bilateral), uma vez que a especificidade de ativos e a recorrência da 
transação justificam tais estruturas, demandando a concepção de mecanismos para preencher as lacunas contratuais e realizar as adaptações necessárias às circunstancias.

Pelo quadro 5, observa-se a utilização do desempenho de fornecedores, mensurado via indicadores de avaliação já apresentados no quadro 4, como uma das ações que permitem tal monitoramento. A realização de inspeções, auditorias, análise documental, mapeamento de fornecedores críticos, que objetivam, entre outros, a observância dos requisitos contratuais assumidos, verificação do desempenho técnico e consumo contratual, bem como avaliações de fornecimento, fazem parte das ações de monitoramento divulgadas, que apesar de envolver um relacionamento diádico, parece não levar em consideração o contexto interorganizacional.

Do exposto, entende-se que as ações de monitoramento visam controlar a relação inteorganizacional à montante da cadeia de suprimento. $O$ controle inteorganizacional é alvo de pesquisas em que: incentivos aos boundary spanners (Dekker, 2016); estabelecimento de metas (Bedford, Malmi \& Sandelin, 2016); previsões de demandas, comparações entre o orçamento planejado e o real, ciclo de tempo, informações de custos de produtos (Lopes et al., 2014); orçamentos interorganizacionais, custeio alvo, sistema de gestão de custos (Gonzaga, et al, 2014) e medição de desempenho de empresas individuais no contexto da cadeia de suprimento (Bhagwat \& Sharma, 2007; Chia, Goh \& Hum, 2009; Callado \& Jack, 2015) são algumas de suas práticas.

No entanto, ao cotejar essas práticas de controle gerencial com aquelas divulgadas pelas empresas da amostra, percebe-se coincidência apenas em relação à avaliação de desempenho de fornecedores, porém sem observância do alinhamento entre os interesses individuais dos parceiros (principalmente da empresa focal) e aqueles decorrentes da parceria. Caglio e Ditillo (2008) citado por Dekker (2016) corroboram com este entendimento ao chamarem atenção com críticas as pesquisas anteriores sobre controle gerencial interorganizacional por estas terem variáveis e estruturas que foram originalmente desenvolvidas para descrever os controles gerenciais interno das empresas, sem considerar sua adequação ao contexto da aliança acriticamente transplantados.

Quanto aos canais de relacionamento com fornecedores, as empresas que os divulgaram revelam a utilização de variadas práticas, conforme quadro 6 . Destaca-se o predomínio da utilização de canais de relacionamento predominante virtuais, com apoio da tecnologia da informação, sendo raro as divulgações de encontros presenciais para fins de comunicação.

\begin{tabular}{|l|l|}
\hline \multicolumn{1}{|c|}{ Empresa } & \multicolumn{1}{|c|}{ Canais de Relacionamento com Fornecedores } \\
\hline AES TIETE & $\begin{array}{l}\text { Fornecedor Conectado - publicação Trimestral enviada a todos os } \\
\text { fornecedores via e-mail; E-mail exclusivo; site do Índice de Desenvolvimento } \\
\text { do Fornecedor (IDF). }\end{array}$ \\
\hline AMPLA ENERG & $\begin{array}{l}\text { Website, portal de relacionamento com fornecedores; grupos de trabalho } \\
\text { com fornecedores de materiais e serviços; Pesquisa indicador de líderes de } \\
\text { opinião externo; Ouvidoria de fornecedores. }\end{array}$ \\
\hline GRUPO EDP & $\begin{array}{l}\text { Áreas de Logística e Compras; Encontro anual com fornecedores; internet; } \\
\text { Pesquisa de satisfação; Relatório anual; Canal de ética; Canal de } \\
\text { sustentabilidade; Adoção de ferramenta eletrônica de formalização digital de } \\
\text { contratos por meio de certificado digital. Reuniões. }\end{array}$ \\
\hline
\end{tabular}




\section{(9)REUNIR}

\begin{tabular}{|l|l|}
\hline CELPE & $\begin{array}{l}\text { Encontros e seminários para troca de melhores práticas entre as empresas } \\
\text { parceiras. }\end{array}$ \\
\hline CEMIG GT & $\begin{array}{l}\text { Portal de compras; E-mails de reclamações e sugestões; Contato e interação } \\
\text { com os fornecedores feito por contato telefônico ou email; Publicações no } \\
\text { Diário oficial, PEC - durante o pregão eletrônico, fax, correspondência, } \\
\text { reuniões e visitas, para resolução de questões específicas. }\end{array}$ \\
\hline CPFL & $\begin{array}{l}\text { Jornal do Fornecedor: periódico mensal que contempla questões internas a } \\
\text { suprimentos, com divulgação de práticas de sustentabilidade, notícias sobre o } \\
\text { grupo CPFL; Portal de fornecedores. }\end{array}$ \\
\hline GER PARANAP & $\begin{array}{l}\text { Evento de sensibilização e engajamento dos fornecedores aos padrões de } \\
\text { saúde e segurança da companhia. }\end{array}$ \\
\hline LIGHT & Portal dos fornecedores. \\
\hline TRACTEBEL & $\begin{array}{l}\text { Comitê de Ética dispõe de um canal de comunicação para que qualquer } \\
\text { pessoa possa entrar em contato de forma anônima e confidencial. }\end{array}$ \\
\hline CTEEP & Participação em eventos para fortalecer o relacionamento com fornecedores. \\
\hline
\end{tabular}

Quadro 6-Canais e políticas de relacionamento

Fonte: Dados da pesquisa (2016)

No contexto das relações interorganizacionais, canais de relacionamento mais eficazes podem contribuir para fomentar a confiança entre os parceiros que, para Uddin e Hassan (2011) a presença de confiança nas relações entre empresas promove a recorrência da transação. Consequentemente, operações repetidas reduzem os custos de transação de seleção, avaliação e custo transacional de parceiros.

Por fim, os mecanismos de estímulo, incentivo e apoio ao desenvolvimento relatados pelas empresas analisadas em seus relatórios de sustentabilidade abrangem a instituição de prêmios, com vantagens pecuniárias ou não, treinamentos, workshops, seminários e eventos que objetivam disseminar os padrões adotados pela empresa focal aos seus fornecedores.

Apesar de declararem como apoio ao desenvolvimento dos seus parceiros de negócio à montante da cadeia de suprimento, cabe uma indagação: tais práticas podem se configurar em demonstração de assimetria de poder da empresa focal na busca pela redução dos seus custos de transação?

\section{CONSIDERAÇÕES FINAIS}

Conclui-se que os mecanismos de controle sobre o relacionamento com fornecedores que são divulgados pelas companhias elétricas listadas na BM\&Fbovespa, principalmente no que se referem às ações de monitoramento, referem-se ao tipo de informação mais evidenciada nos relatórios de sustentabilidade, sugerindo a importância dada por essas empresas focais ao controle de suas relações interorganizacionais. Tais mecanismos de controle contribuem para ratificar o entendimento das estruturas de governança do tipo híbrido e hierárquico (na forma bilateral), uma vez que a presença de especificidade de ativos e a recorrência da transação justificam tais estruturas, demandando a concepção de 


\section{(9)REUNIR}

mecanismos para preencher as lacunas contratuais e realizar as adaptações necessárias às circunstancias.

Adicionalmente, ao cotejar esses mecanismos de controle com as práticas de controle gerencial se percebe coincidência apenas em relação à avaliação de desempenho de fornecedores, porém sem observância do alinhamento entre os interesses individuais dos parceiros (principalmente da empresa focal) e aqueles decorrentes da parceria.

\section{REFERÊNCIAS}

ALVES, J. N.; PEREIRA, B. A. D.; KLEIN, L. L. Avanços e Tendências nos Relacionamentos Inteorganizacionais: um paralelo entre estudos brasileiros e internacionais. REGE, v. 20, no. 1, p. 3-20, jan./mar. 2013.

BARBOSA, R. V. do N. Controle Gerencial no Relacionamento com empresas terceirizadas: um estudo de caso no setor elétrico com o uso da análise do discurso e da teoria institucional. Tese de Doutorado. Universidade de São Paulo, 285p., São Paulo, 2012.

BEDFORD, D. S.; MALMI, T.; SANDELIN, M. Management control effectiveness and strategy: An empirical analysis of packages and systems. Accounting, Organizations and Society. v. 51, p.12-28, May, 2016 (in progress).

CALLADO, A. A. C.; JACK, L. Balanced scorecard metrics and specific supply chain roles. International Journal of Productivity \& Performance Measurement, V. 64, n. 2, pp. 288230, 2015.

DEKKER, H. C. On the boundaries between intra firm and inter firm management accounting research . Management Accounting Research. v. 31, p. 86-99, jun. 2016.

FIANI, R. Teoria dos Custos de Transação. In: KUPFER, David; HASENCLEVER, Lia (Org.). Economia Industrial: fundamentos teóricos e práticas no Brasil. Rio de Janeiro: Campus, 2002.

GONZAGA, R. P.; AILLÓN, H. S.; FEHR, L. C. F. de A.; BORINELLI, M. L.; ROCHA, W. Mecanismos Disciplinadores da Gestão de Custos Interorganizacionais e Economia dos Custos de Transação: um ensaio teórico. REPeC - Revista de Educação e Pesquisa em Contabilidade, v.9, n.o 3, jul./set. 2015.

HENNART, J. Perspectivas de Custos de Transação em Relações Interorganizacionais. In: CROPPER, Steve et al. Handbook de Relações Interorganizacionais da Oxford. Porto Alegre: Bookman, 2014.

LOPES, L. da C.; MEIRA, J. M. de; LIBONATI, J. J.; SANTOS, A. A. dos; CALLADO, A. L. C. Práticas de Contabilidade Interorganizacional em Indústrias de Médio e Grande Porte Instaladas na 


\section{(9REUNIR}

Região Metropolitana de Recife. Revista Ciências Administrativas. v. 20, n. 2, jul./dez. 2014.

MOURITSEN, J.; THRANE, S. Accounting, network complementarities and the development of inter-organizational relations. Accounting, Organization and Society, v. 31, p. 241-275, 2006.

PEREIRA, A. N. O Controle Gerencial em Redes de Negócios: um estudo de caso no segmento de livrarias. Tese de Doutorado, 256 f. USCS - Universidade Municipal de São Caetano do Sul, SP, 2014.

QUINTART, A.; ZISSWILLER, R. Teoria Financeira. Lisboa: Editora Caminho S.A., 1985

SANTANA, E. A. de; OlIVEIRA, C. A. C. N. V. de. Análise da indústria de energia elétrica do Brasil: abordagem através da economia dos custos de transação. Pesquisa e Planejamento Econômico - PPE, Rio de Janeiro, v. 29, n. 2, p. 273-294, ago. 1999

UDDIN, M. B.; HASSAN, M. R. Conceptual framework of interorganizational cost management: A critical analysis. ASA University Review, v. 5, n. 2, p. 1-14, 2011.

WILLIAMSON, O. E. Transaction-Cost Economics: The Governance of Contractual Relations. Journal of Law and Economics. v. 22, no. 2, p. 233-261, 1979.

The Economics of Organization: The Transaction Cost Approach. American Journal of Sociology, v. 87, no 3, p. 548-577, 1981.

- Transaction Cost Economics: An Introduction. Economics Discussion Papers. March, 2007. 